Journal of Social and Development Sciences

Vol. 4, No. 6, pp. 258-267, June 2013 (ISSN 2221-1152)

\title{
A Proposed Framework for E-Commerce Usage and Competitive Advantage on Small and Medium Tourism Enterprises (SMTES) in Lebanon
}

\author{
Firas Halawani*, Muhammad Madi Bin Abdullah, Muhammad Sabbir Rahman, Yahya halawani \\ Multimedia University, Cyberjaya, Selangor, Malaysia \\ *firas_halawani87@yahoo.com
}

\begin{abstract}
E-commerce has tremendous potential for creating business opportunities, tourism as information intensive industry can gain important synergies from the use of e-commerce. Small and medium sized tourism enterprises should take advantage of the e-commerce and refocus their business strategies to maintain their competitiveness in order to avoid being replaced. This paper discusses the current literature on the e-commerce usage and competitive advantage in small and medium tourism enterprises (SMTEs), and proposes a conceptual framework to be tested in the context of Lebanon. This paper adopted a content analysis to examine number of articles that were published by major tourism and e-commerce usage journals. This paper provides a conceptual framework, which mainly based on the e-commerce readiness model, which has been used to assess the e-commerce usage at firms' level. Also provides a revised ICDT model to explore how tourism enterprises are exploiting the internet spaces and to measure the level of sophisticated use of internet among tourism SMEs. This paper improves knowledge on how small tourism enterprises exploit Internet spaces (ICDT) to improve their competitiveness.
\end{abstract}

Keywords: Competitive advantage, E-commerce, ICDT, SME, Tourism

\section{Introduction}

Tourism considered as an important sector in the economy of many countries, due to the income generated by the consumption of goods and services by tourists, and the income from imposed taxes on businesses in the tourism industry, as well as tourism creates a huge opportunities for people to work in tourism-related service industries. Travel and tourism industry services includes, transportation services such as airlines, cruise ships and taxis, hospitality services, such as accommodation, including hotels and resorts, and entertainment venues, such as parks, casinos and shopping malls, music venues and theaters. Simply using Internet as a means to establish presence or to become known to the Internet users is not enough. There has to be a more deep approach and as Porter (2001), claimed Internet technology must be used to reconfigure traditional activities. Researchers agree that the contribution made by the tourism sector in developing economies is substantial. However, SMTEs are noted for their failure to derive optimal benefits from using the Internet for business to improve their competitiveness (Murphy and Kielgast, 2008). With respect to the explanation about the internet spaces and the level of sophistication use of the spaces by Angerhn (1997) and due to the rapid growth of internet use and web technology and its expansion to include many functions. Therefore, this paper discusses the current literature on the e-commerce usage and competitive advantage in small and medium tourism enterprises (SMTEs), and proposes a conceptual framework to be tested in the context of Lebanon.

\section{Literature Review}

In following paragraphs will discuss the theoretical foundations that lie behind the development of the framework. The framework has three purposes: The first purpose is to identify the most relevant determinants of e-readiness (what factors collectively contribute to the e-readiness of a business, both negatively and positively). The second purpose is to identify measurement tool to assess the sophisticated use of internet for SMTEs based on their level of e-readiness. The final purpose is to build conceptual framework for the research in order to explore the impact of the e-commerce usage on the competitive advantage for tourism SMEs. 
E-readiness: E-readiness defined as a complex multi layered phenomenon, it has several dimensions, including telecommunications infrastructure, human resources, and legal and policy framework (Gammack, 2004). At the country level, e-readiness refers to the ability of a country to take advantage of ICTs as an engine of economic growth and human development. While others defined "The network readiness of a country indicates the ability of its principal stakeholders - government, citizens, businesses - to leverage the potential of information and communication technology" (Gunasekaran and Harmantzis 2007). "E-readiness (electronic readiness) is a measure of the degree to which a country, or nation or economy may be ready, willing or prepared to obtain benefits which arise from information and communication technology (ICTs)" (Dada 2006). Although most e-readiness tools are developed as a means of assessing or ranking countries, there are few researchers and academics have examine the e-readiness of business and individuals within a country. Molla and Licker (2005) applied e-readiness to examine business readiness to adopt e-commerce. At this level e-readiness is described as: An organization's assessment of the e-commerce, managerial, organizational, and external situations in making decisions about adopting e-commerce. (Molla and Licker, 2005). This study does not focus on global e-readiness it focuses on the e-readiness of a particular type of business - SMTEs in Lebanon. The Internet has become one of the most popular mediums for researching, planning, and transacting travel by customers. Furthermore, e-commerce offers significant benefits for SMTEs, and it continues to be used heavily by many other tourism entities. This means that SMTEs that do not adopt the Internet face the reality of becoming uncompetitive.

Table 1: E-readiness tools

\begin{tabular}{|c|c|c|c|c|}
\hline Tool & Type & Summery & Authors & source \\
\hline $\begin{array}{l}\text { E-readiness } \\
\text { ranking }\end{array}$ & E-economy & $\begin{array}{l}\text { Connectivity and technology, } \\
\text { business environment, consumer } \\
\text { and business adoption, legal and } \\
\text { policy environment, social and } \\
\text { cultural infrastructure, } \\
\text { supporting e-services }\end{array}$ & $\begin{array}{l}\text { Economist } \\
\text { Intelligence Unit }\end{array}$ & (EIU.2005) \\
\hline $\begin{array}{l}\text { ASEAN } \\
\text { Readiness }\end{array}$ & E-society & $\begin{array}{l}\text { Readiness for the digital } \\
\text { economy and the development of } \\
\text { the ASEAN information } \\
\text { infrastructure. Measures e- } \\
\text { society, ecommerce, e- } \\
\text { government, liberalizing trade in } \\
\text { ICT goods and services and } \\
\text { infrastructure }\end{array}$ & IBM, E-ASEAN & $\begin{array}{l}\text { (Bhatia \& IBM } \\
\text { Singapore.2001) }\end{array}$ \\
\hline $\begin{array}{l}\text { Asian Pacific } \\
\text { Economic } \\
\text { Cooperation's } \\
\text { (APEC)'s } \\
\text { Ecommerce } \\
\text { Readiness } \\
\text { Assessment }\end{array}$ & E-economy & $\begin{array}{l}\text { Basic infrastructure and } \\
\text { technology, access to necessary } \\
\text { services, level /type of use of } \\
\text { Internet, promotion and } \\
\text { facilitation activities, skills and } \\
\text { human resources, positioning for } \\
\text { the digital economy }\end{array}$ & $\begin{array}{l}\text { Asian Pacific } \\
\text { Economic } \\
\text { Cooperation }\end{array}$ & (APEC 2000) \\
\hline
\end{tabular}

Source: Bridges.org (2005)

The Bridges Organization ${ }^{1}$ categorized e-readiness tools based on whether they focus on 'e-society' or 'eeconomy'. Table 1 listed of some of the e-readiness tools, and the areas that they focus on. There are a number of similarities shared between each tool, for instance, connectivity (or access to the telecommunications infrastructure), human capital, and policy considerations are common to all 'e-economy' tools. These are also the most commonly cited reasons for the slow diffusion of ICTs in developing countries.

\footnotetext{
${ }^{1}$ Bridges.org is an international organization with a mission to promote the effective use of information and communications technology (ICT) in the developing world for meaningful purposes, such as better healthcare, education and self-sustaining economic development.
} 
Technology adoption: Nowadays, information technology (IT) considered as an essential tool in improving and enhancing the competitiveness of the economy of developed and developing countries .The use of information technology on large-scale has significant effects on the productivity of firms. Therefore, it is necessary to understand the determinants of the IT adoption and to reviewing the theoretical models in the literature that are related to the IT adoption. A number of authors have written about the adoption of technological innovation. For instance, Tornatzky and Fleischer (1990) discussed technology innovation amongst businesses, while Iacovou et al., (1995) discussed electronic data interchange (EDI) adoption amongst small businesses. More recently, Molla and Licker (2005) discussed e-commerce adoption amongst businesses in developing countries. Each of these studies identified adoption as drivers and inhibitors, and factors that require consideration by businesses when making decisions about adopting new technology.

Tornatzky and Fleischer (1990) proposed a TOE model, the theory context consist of three elements: technological, organizational and environmental context. These aspects explain of an enterprise's context that influences the process adopting and implementing a technological innovation. Technological context focused on a firm's current and new technology that could influence the firm's ability to conduct E-business or other technology implementation. Past technology, usage and computer facilities owned by companies were some of the construct measurements. Organizational context referred to descriptive measures of organizations for instance internationalization scope, size of organization and managerial beliefs. Environmental context focused on the environment of the business or the industry's external factors that might affect the firm's for instance legal protection and government's regulation (Oliveira and Martins, 2011). The TOE framework provided a useful analytical framework that can be used for studying the adoption and assimilation of different types of IT innovation. The TOE framework has a solid theoretical basis, being used extensively as theoretical foundations in studies on technology usage/ adoption/ implementation.

\section{Figure 1: The context of technological innovation}

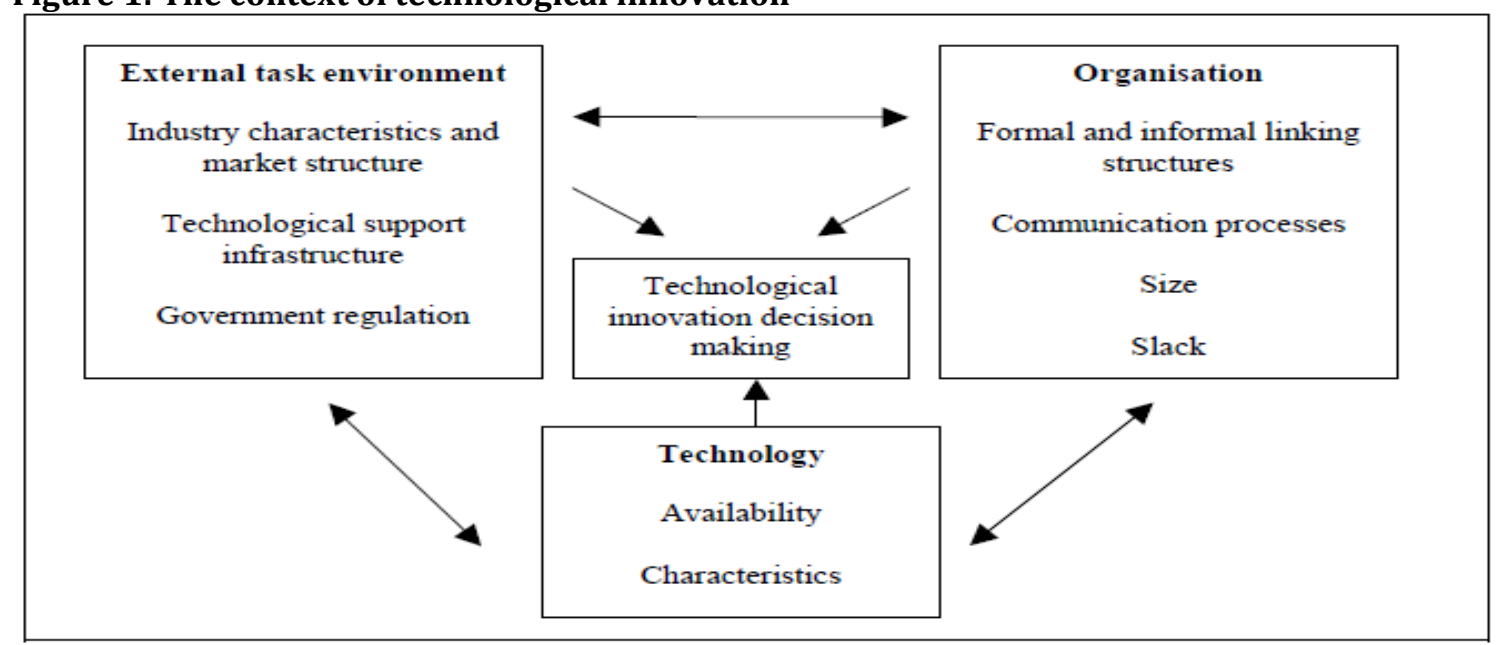

Source: Adapted from Tornatzky and Fleischer (1990)

Several authors used the TOE framework to understand different IT adoptions, such as: electronic data interchange (EDI); open systems; web site; e-commerce; enterprise resource planning (ERP); business to business (B2B) e-commerce; e-business; knowledge management systems ( Oliveira and Martins, 2008; Oliveira and Martins, 2009; Liu, 2008; Pan and jag, 2008; Salwani et al., 2009). In the context of businesses in developing countries, Molla and Licker (2005) conducted a study to examine e-commerce adoption amongst businesses. The study aimed to identify environmental challenges and the limitations that are different to those experienced in developed economies. The authors developed and empirically tested an e-readiness model called the Perceived E-commerce Readiness Model (PERM). The model considered some internal organizational factors, known as perceived organizational e-Readiness (POER), and external factors, identified as perceived external e-Readiness (PEER), as important for e-commerce adoption. The authors defined POER to comprise the following: 
- The organization's perception, comprehension, and projection of e-commerce and its potential benefits and risks.

- The commitment of its managers.

- Key organizational components, such as its resources, processes, and business infrastructure.

Whilst PEER represents an organization's assessment and evaluation of relevant external environmental factors such as Government e-Readiness, Market Forces e-Readiness and Support Industries e-Readiness. The authors further claim that PERM can assist organizations in developing countries to locate, measure and manage risks in e-commerce adoption activities. As can be observed in Figure 2, the model identifies two contextual areas (Perceived Organizational e- Readiness) and (Perceived External e-Readiness) that consist of a number of subsequent factors. PERM model has been used with several studies, for instance (Dada, 2006; Karanasios, 2008; Boateng et al., 2009).

\section{Figure 2: Perceived E-commerce Readiness Model (PERM)}

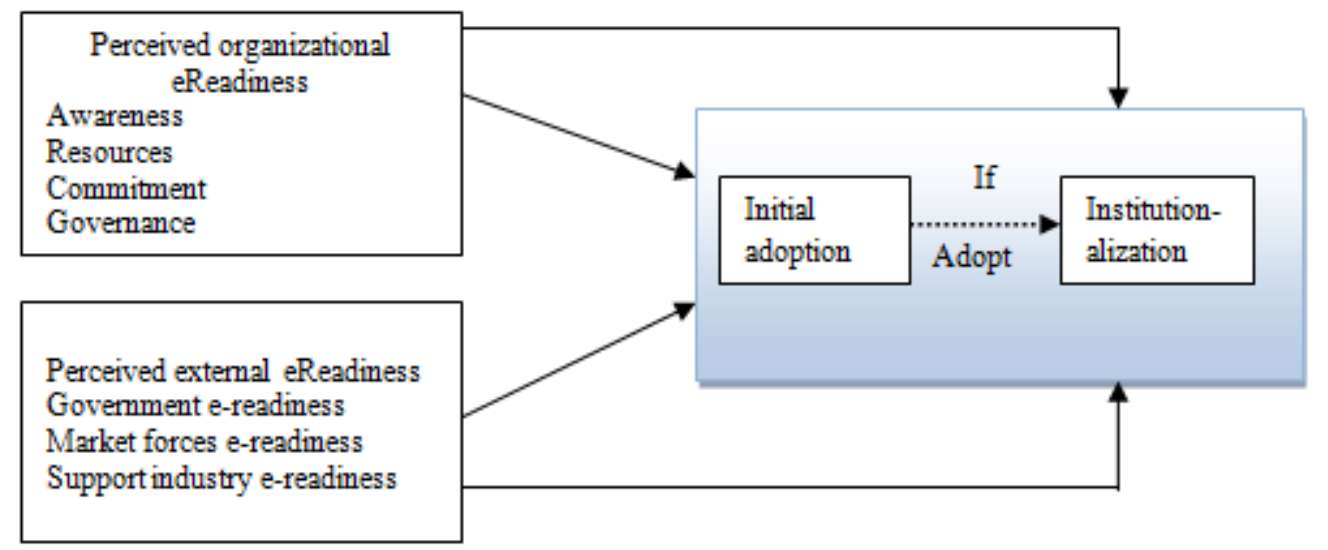

Source: Molla and Licker (2005), Figure 2, p.881

Tan, Tayler and Manica (2007) analyzed E-commerce adoption by businesses in China from internal, external and contextual perspectives. They validated and tested the Perceived e-Readiness Model in China and they gave credit to the PERM as it is more comprehensive than earlier models, examines e-commerce institutionalization, and for its inclusion of extensive external environmental and internal organizational issues. Karanasios (2008) proposed an e-commerce framework for small tourism enterprises in developing countries, the framework identified factors that contribute to the e-readiness of a business into three contextual areas. The first contextual area is the enabling Environment; which refers to an assessment of ecommerce enablers such as supporting industries and government readiness. The second contextual area is market readiness; which refers to an assessment of the market environment. In regards to the tourism industry, an investigation of the market environment is likely to reveal the main ecommerce adoption drivers such as customer, competitor and supplier/ partner readiness. The third contextual area is organizational readiness; which refers to an assessment of the business readiness to adopt e-commerce. It is here that a business is likely to encounter many obstacles to ecommerce. With regard to the purpose of this research, which is the e-commerce usage and its impact on competitive advantage among Lebanese tourism SMEs, therefore, the perceived e-commerce readiness model has been chosen for this study in order to determine the factors collectively contribute to the e-readiness of a business in SMTEs. Each of the contextual areas and related factors are described in Table 2. 
Table 2: Description of the variables in the PERM

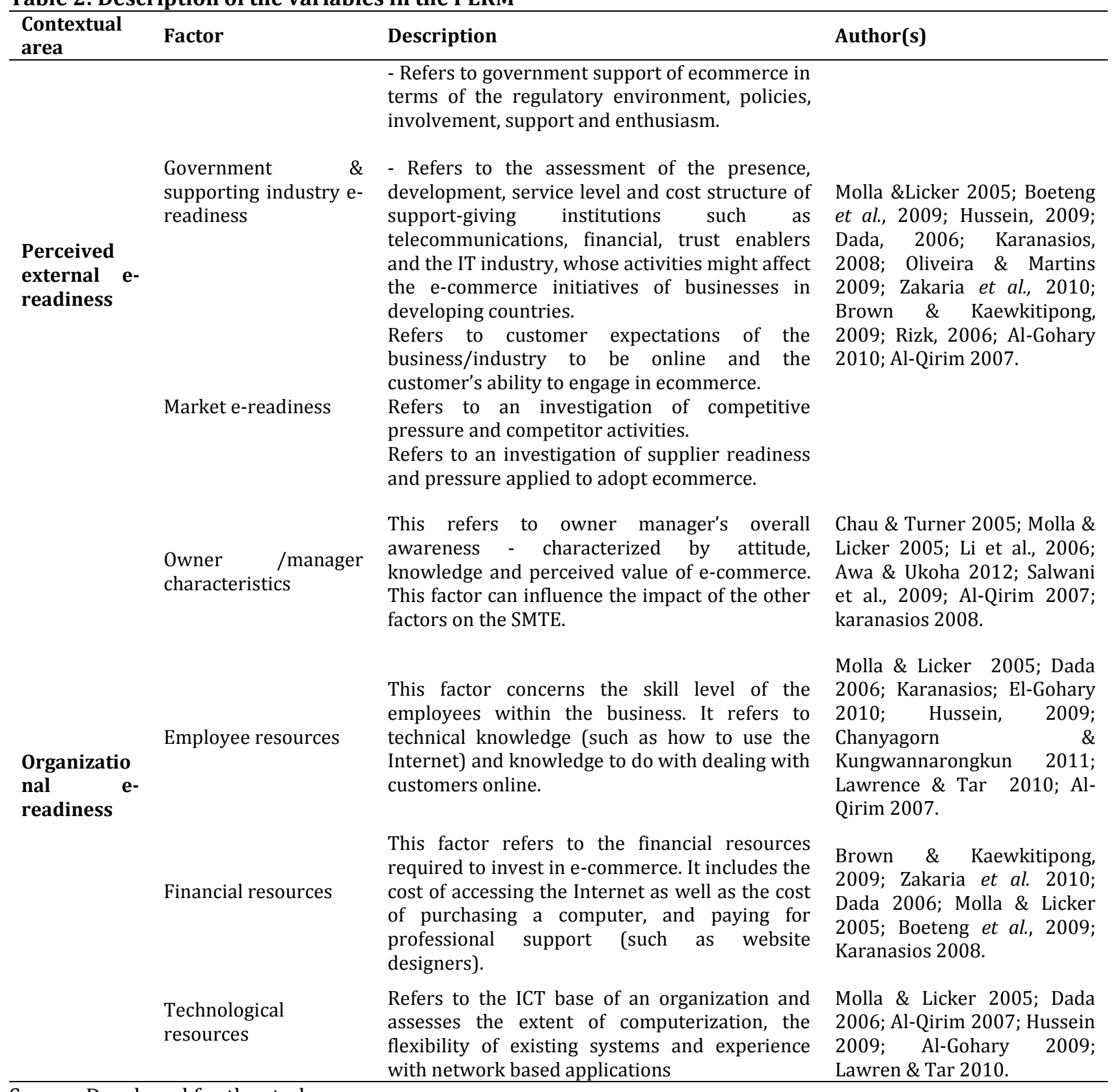

Source: Developed for the study

\section{Sophisticated use of the Internet}

Internet has tremendous potential for creating business opportunities, tourism as information intensive industry can gain important synergies from the use of the Internet. Small and medium sized tourism enterprises should take advantage of the Internet and refocus their business strategies to maintain their competitiveness in order to avoid being replaced. The previous section discussed technology adoption tools and the factors that collectively contribute to the e-readiness of a small enterprise. In this section will discuss the literature available to identify measurement tool to assess the sophisticated use of internet for SMTEs based on their e-readiness. ICDT model it's one of the first strategic framework for mature Internet business practice proposed by Albert Anghern (1997), the model categorized the opportunities created by the Internet into four different virtual spaces (Information, Communication, distribution, Transaction). However, from a 
comprehensive study of the literature available, it is evident that there is a dearth of research that used ICDT model to assess the sophisticated use of Internet in the travel and tourism enterprises namely O'brien (1998) and Karanasios (2008). With respect to the explanation about the internet spaces and the level of sophistication use of the spaces by Angerhn (1997) and due to the rapid growth of internet use and web technology and its expansion to include many functions, there is a need to reconsider the ICDT model to include all the changes on the internet virtual spaces, which were not discussed in any study before. In this context, the improvement of ICDT model came after a comprehensive review for more than 40 latest studies in tourism field, as it mentioned in the literature above.

\section{Figure 3: Tourism and ICDT model}

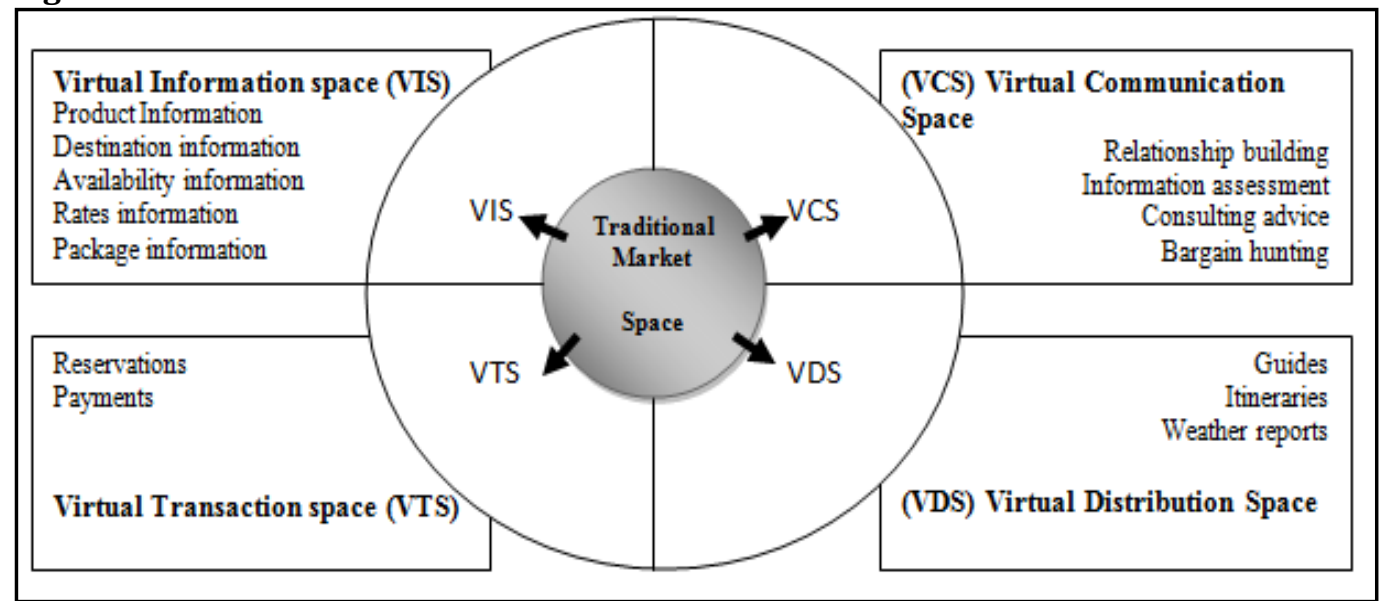

Source: O’brien 1998, Figure 2, p, 72

Few studies have applied the ICDT model in tourism industry (O'brien, 1998; Karanasios, 2008). The use of websites in tourism enterprises was very common and most enterprises had a website. Besides, it is important to explore how tourism enterprises are exploiting the Information Space and what information was provided (Karanasios, 2008). The ways enterprises were exploiting the space can be grouped into four areas (website, intermediary/portal website, government website, collaborative website). In other hand, Karanasios (2008) did not discuss widely the power of search engine marketing on website visibility and accessibility, also the effect on managers/ owners for selecting the collaborative sites based on search engine ranking. The search engines are an important part not only for general use of the Internet, but also in a travel information search (Xiang et al., 2008). The Search Engine Marketing (SEM) can be divided into two categories: Pay for Performance (PFP) where the website pays for visibility (using links, advertising banners, sponsored links or buying 'words) and Search Engine Optimization (SEO) where the website's visibility is optimized by making technical adjustments (using keywords, meta-tags) (Murphy and Kielgast, 2008). The information search is moving to online social network where people's interacted freely and exchange information and also by using sites of individual suppliers and intermediaries (Buhalis et al., 2011). O'brien (1998) and karanasios (2008) didn't include the social network sites (such as Facebook, Twitter, etc) in their studies, as an intermediary which can tourism enterprises use it to promote their business and to offer information to potential customers. Thus, it is necessary to consider social network sites as effective tool can exploit it for information space; SNS enables tourism companies to reach potential customers in a costeffective way without the need of additional hardware or software (Kasavana et al., 2010).

With regard to the communication space, O'brien (1997) and karanasios (2008) determined that the main application of this space was to use it for the exchange of information with the various stakeholders, such as customers, suppliers, and strategic partners. The authors also noted that email is the most widely used Internet activity by small businesses in developing countries and it is the most cost effective and easily adopted. In addition, with the traditional communication tools, Internet provided new functions that allow interaction with potential customers. For instance, the consumer centric marketing (CCM) will be expected as the norm in the travel industry by customers of the future, this tool help to stimulate communication with consumers such as User Accounts - Online Surveys/ customer complaints (Niininen et al., 2007). By 
addressing the limitations of the above studies, we proposed a revised ICDT model as displays in Figure 4. The figure illustrates how each of the three spaces was exploited and what of each space was used for.

Figure 4: A revised ICDT model for travel and tourism industry

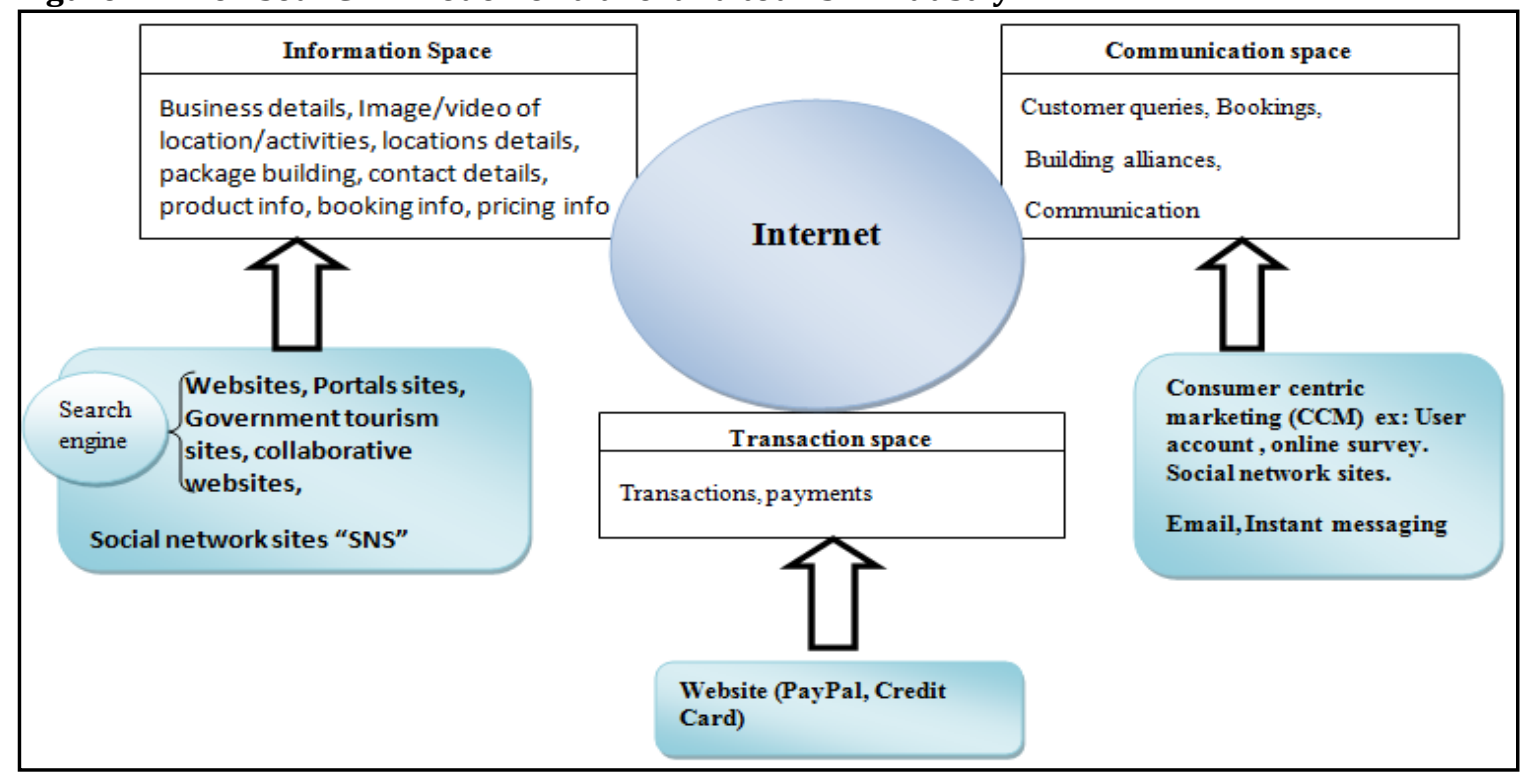

Source: Halawani et al. (2012)

Competitive advantage: Tourism is a highly competitive business in a world of destinations. The use of EBusiness for marketing hotel \& tourism services by Hotel Management and travel companies is becoming increasingly popular around the globe. The hospitality \& tourism industry has always been among the first to capitalize on new technology. Because it is an information rich industry, it depends heavily on finding and developing new means to distribute travel \& hospitality services, and providing comfort and convenience to travelers. In addition, consumers are constantly seeking new sources of information to assist them make decisions before purchasing travel services to make their trip more satisfying. By providing an affordable platform to differentiate their product from that of competitors, ICTs plays a critical role in the competitiveness of tourism organizations and destinations (Buhalis and Law, 2008). One fundamental principle will always lead to a competing advantage; if a destination website is perceived as useful, it may influence the customer to visit the destination (Kaplanidou and Vogt, 2006). Buhalis (2002) defined the following generic strategies for competitive advantage in travel and tourism industry:

Cost leadership refers to strategy used by businesses to create a low cost of operation within their niche. The use of this strategy is primarily to gain an advantage over competitors by reducing operation costs below that of others in the same industry. Cost leadership may emerge, for example, from standardizations, economics of scale or better deals with suppliers.

Differentiation can be achieved by creating products through a unique selling proposition or services that are appreciated industry-wide as being unique and valuable.

Focus refers to the strategy in which a narrow competitive scope within an industry, such as a particular buyer group, a segment of the product line, or a geographical market, is targeted and a cost leadership or differentiation strategy is tailored exclusively for its needs.

Time can be regarded as an additional potential source for competitive advantage (Buhalis 2002). Jayawardena et al. (2008) recommend three strategies (not dependent on the user) that can be implemented by SMTEs to improve their competitiveness: targeted consumers, product Differentiation, SMTE's Brand.

\section{Research framework}

Collections and innovations of prior theories and models that highlighted positivistic research helped the researcher in developing the theoretical framework. Referred as "a conceptual model on how one theorized 
or made logical sense of the relationships among the several factors under study" (Sekaran, 2003), it discussed and helped the hypothesis development with the aim to further understand the situation.

Dependent Variable: Based on Hussey and Hussey (1997), the values of dependent variable were predicted by independent variable. Empirical investigation on other variables that influenced dependent variable enabled researchers to seek for answers of an issue (Sekaran, 2003).

Independent Variable: Acted as a predictor (either positive or negative), independent variables enabled values manipulation of dependent variable (Hussey \& Hussey, 1997). The increase in a unit of independent variable could lead to an increase or decrease in dependent variable (Sekaran, 2003).

Intervening variable: A variable that explains a relation or provides a causal link between other variables. Also called by some authors "mediating variable" or "intermediary variable." It referred to "one that surfaced between the time the independent variables started operating to influence the dependent variable and the time their impact is felt on it" (Sekaran, 2003). It was influenced by the original independent variable, and affected the original dependent variable.

In the current study, competitive advantage was the variable of primary interest. In assessing the factors determining of E-commerce usage and its impact on competitive advantage among Lebanese SMTEs. In the conceptual framework for this study, government \& supporting industry e-readiness, Market e-readiness, Owner/manager characteristics, employee resources, financial resources, technological resources, information, and communication and transaction space were classified as independent variables. Those variables will examine to identify their impact on the competitive advantage (dependent variable). Ecommerce usage represented both dependent and independent variables. It also fulfilled the function of intervening variable as defined by Robson (1993), for which it might be affected by dependent variables, and also affecting the original dependent variable, competitive advantage.

\section{Figure 5: Proposed Conceptual framework}

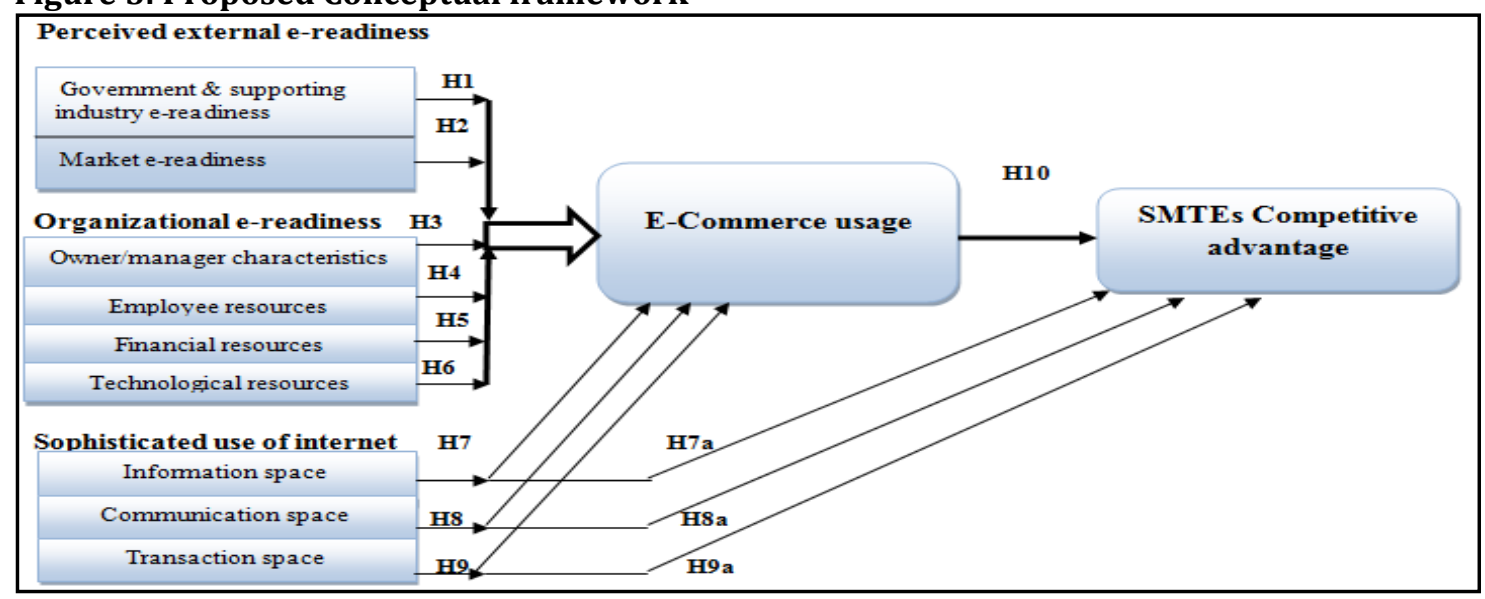

\section{Conclusion}

This paper reviews the current literature on the e-commerce usage and competitive advantage in small and medium tourism enterprises (SMTEs) and the development of Internet usage in the tourism and hospitality industries in the past few years. It enables readers in general, and tourism and hospitality (SME) managers in particular, to better understand from the latest research findings how can exploit the Internet opportunities to gain high performance and competitiveness. Having analyzed the content of papers, the use of website was very common and apparently became a norm for tourism enterprises. But, simple use and sophisticated use of internet in general and websites in particular, may vary from enterprise to another, therefore, this paper provides to knowledge a framework for e-commerce usage and competitive advantage in SMTEs, This framework improves knowledge on how small tourism enterprises exploit Internet spaces (ICDT) to improve their competitiveness. Despite its contribution, a major limitation of this paper is the inclusion of a numbers of articles from research journals and the exclusion of other publications and also only focus in ICDT 
variables. As such, it would be worthwhile for similar future reviews to extend the coverage of articles from tourism and hospitality journals and also the period of analysis.

\section{References}

Angehrn, A. (1997). Designing mature Internet business strategies: the ICDT model. European Management Journal, 12(4), 361-369.

Al-Qirim, N. A. (2007). E-commerce adoption in small businesses-cases from New Zealand. Journal of Information Technology Case and Application Research, 9(2), 28-57.

Brown, D. H. \& Kaewkitipong, L. (2009). Relative size and complexity: e-business use in small and medium sized tourism enterprises in Thailand. Journal of Enterprise Information Management, 22(1/2), 212231.

Boateng, R., Molla, A., Heeks, R. \& Hinson, R (2009). Advancing E-commerce beyond readiness in a developing economy: experiences of Ghanaian firms. Journal of electronic commerce in organizations. Retrieved 15 April 2013 from http://ctbus.files.wordpress.com/2010/10/ecommerce-in-ghanaboatheeksmollahinson.pdf

Buhalis, D. (2002). Information Technology and Tourism: Trends and Developments, Estudis de Turisme de Catalunya. Tourism Studies of Catalonia, 6(10), 21-26

Buhalis, D. \& Law, R. (2008). Progress in information technology and tourism management: 20 years on and 10 years after the Internet - The state of e-tourism research. Tourism Management, 29(4), 609- 623.

Buhalis, D., Leung, D. \& Law, R. (2011). eTourism: Critical Information and Communication Technologies for Tourism Destinations, in Wang, R., and Pizam, A., (Eds), Destination Marketing and Management, CAB International, ISBN 9781845937621, 205-224.

Chanyagorn, P. \& Kungwannarongkun, B. (2011). ICT readiness assessment model for public and private organizations in developing country. International journal of information and education technology, $1(2), 99-106$.

Dada, D. (2006). E-readiness for developing countries: moving the focus from the environment to the users. Electronic Journal of Information Systems in Developing Countries, 27(6), 1-14.

El-Gohary, H. (2012). Factors affecting e-marketing adoption and implementation in tourism firms: an empirical investigation of Egyptian small tourism organizations. Tourism management, 33, 12561269.

Gammack, J. (2004). Asia Pacific Economic Cooperation (Organization). Tourism Working Group, Griffith University School of Management. \& APEC International Centre for Sustainable Tourism. 2004, Development needs of small to medium size tourism businesses: a report prepared for APEC Tourism Working Group, School of Management Griffith Business School Griffith University.

Gunasekaran, V. \& Harmantzis F. (2007). Emerging wireless technologies for developing countries. Technology in society, 29, 23-42.

Halawani, F., Mazumder, M. \& Halawani, Y. (2012). A revised ICDT model for exploring the sophisticated use of Internet among tourism SMEs. Presented at Multi-disciplinary Research in Management Science, International Colloquium, Laval University, Quebec city, Canada.

Hussein, R. (2009). The Adoption of Web Based Marketing in the Travel and Tourism Industry: An Empirical Investigation in Egypt. Doctoral dissertation. University of Nottingham. Retrieved 22 April 2013 fromhttp://etheses.nottingham.ac.uk/1125/1/Rania_Samir_Hussein_Thesis_The_Adoption_of_Web_ Based_Marketing_in_the_Travel_and_Tourism_Industry_An_Empirical_Investigation_in_Egypt.pdf

Hussey, J. \& Hussey, R. (1997). Business research: A practical guide for undergraduate and postgraduate student. Great Britain: Macmillan Press Ltd.

Iacovou, C. L., Benbasat, I. \& Dexter, A. S. (1995). Electronic data interchange and small organizations: Adoption and impact of technology. MIS Quarterly, 19(4), 465-485.

Karanasios, S. (2008). An e-commerce framework for small tourism enterprises in developing countries. Doctoral dissertation. Victoria University. Retrieved 15 May 2013 from http://vuir.vu.edu.au/1515/1/Karanasios.pdf

Li, Y., Tan, C., Teo, H. \& Tan, B. (2006). Innovative usage of information technology in Singapore organizations: Do CIO characteristics make a difference? IEEE Transactions on Engineering Management, 53(2), 177190. 
Martins, M. \& Oliveira, T. (2009). Determinants of e-commerce adoption by small firms in Portugal", Proceedings of the 3rd European conference on information management and evaluation. Gothenburg, Sweden, September, 328-338.

Molla, A. \& Licker, P. S. (2005). E-commerce adoption in developing countries: a model and instrument.

Information \& Management, 42(6), 877-899.

Murphy, H. C. \& Kielgast, C. D. (2008). Do small and medium-sized hotels exploit search engine marketing? International Journal of Contemporary Hospitality Management, 20(1), 90-97.

Niininen, O., Buhalis, D. \& March, R. (2007). Customer empowerment in tourism through consumer centric marketing (CCM). Qualitative Market Research. An International Journal, 10(3), 265-281.

O'Brien, J. A. (1999). Management Information Systems: Managing Information Technology in the Internetworked Enterprise, Irwin/ McGraw-Hill, USA.

Oliveira, T. \& Martins, M. F. (2009). Determinants of information technology adoption in Portugal, ICE-B 2009: Proceedings of the international conference on e-business, Milan. Italy, July, 264-270.

Oliveira, T. \& Martins, M. F. (2010a). Firms patterns of e-business adoption: Evidence for the European union27. The Electronic Journal Information Systems Evaluation, 13(1), 47-56.

Oliveira, T. \& Martins, M, F. (2011). Literature Review of Information Technology Adoption Models at Firm Level. The Electronic Journal Information Systems Evaluation, 14(1), 110-121.

O'Connor, P. \& Frew, A. (2002). The future of hotel electronic distribution: expert and industry perspective. Cornell Hotel and Restaurant Administration Quarterly, 43(3), 33-45.

Porter, M. (2001). Strategy and the Internet. Harvard Business Review, 103D, 63-78.

Sekaran, U. (2003), Research Methods for Business. New York, NY: John Wiley and Sons, Inc.

Teo, T. S. H., Ranganathan, C. \& Dhaliwal, J. (2006). Key dimensions of inhibitors for the deployment of webbased business-to-business electronic commerce. IEEE Transactions on Engineering Management, 53(3), 395-411.

Tornatzky, L. \& Fleischer, M. (1990). The process of technology innovation, Lexington, MA, Lexington Books.

Xiang, Z., Wober, K. \& Fesenmaier, D. R. (2008). Representation of the online Tourism domain in Search Engines. Journal of Travel Research, 47(2), 137-150.

Zelenka, J. (2009). Information and communication technologies in tourism influence, dynamics and trends. E+MEkonomie a Management, 1, 123-131.

Zhu, K. \& Kraemer, K. L. (2005). Post-adoption variations in usage and value of e-business by organizations: Cross-country evidence from the retail industry. Information Systems Research, 16(1), 61-84. 